\title{
IGLESIA Y REPRESENTACIONES DE CLASE EN ARGENTINA A MEDIADOS DEL SIGLO XX. UNA APROXIMACIÓN DESDE LA CULTURA CLASISTA JOCISTA ${ }^{1}$
}

\author{
POR \\ JESSICA BLANCO ${ }^{2}$ \\ Centro de Investigaciones «María Saleme de Burnichón» de la Facultad de Filosofía y \\ Humanidades de la Universidad Nacional de Córdoba (UNC)
}

\section{RESUMEN}

La propuesta de este trabajo es el análisis de las diversas representaciones de clase y dinámicas de relación entre la Juventud Obrera Católica (JOC) argentina y la jerarquía eclesiástica; en relación con miembros de otras organizaciones laicales y en el interior de la asociación, entre asesores eclesiásticos y jocistas.

Parto de la hipótesis que, hacia mediados del siglo xx, las profundas diferencias sociales que caracterizaban la sociedad argentina fueron reproducidas y naturalizadas por la Iglesia, tanto por eclesiásticos como por los laicos. Lo anterior adquiere particular implicancia para el funcionamiento de una asociación autodenominada obrera como la JOC, si va unido a una identificación del trabajador manual como un ser sospechoso y con capacidades de comprensión limitadas. De todas maneras, estas visiones de inferioridad intelectual y social, aceptadas acríticamente por los jocistas, coexistían con autorrepresentaciones de superioridad moral respecto a élites cuestionadas por su egoísmo e hipocresía, lo que contribuyó a profundizar los contrastes de clase y las distancias sociales en el interior de la Iglesia.

PALABRAS CLAVE: JOC- clase- Iglesia- Argentina- representaciones- obrero.

\section{CHURCH AND REPRESENTATIONS OF CLASS IN ARGENTINA TO MIDDLE OF THE XX CENTURY. AN APPROXIMATION FROM THE JOCIST CLASSIST CULTURE}

\begin{abstract}
The proposal of this article is the analysis about the diverse representations of classes and dynamics from the relation between the Juventud Obrera Católica
\end{abstract}

\footnotetext{
${ }^{1}$ Agradezco las observaciones y sugerencias de quienes evaluaron este trabajo en octubre de 2013.

${ }^{2}$ Dra. en Historia e investigadora de CONICET en el Centro de Investigaciones «María Saleme de Burnichón» de la Facultad de Filosofía y Humanidades de la Universidad Nacional de Córdoba.
} 
(JOC) Argentinian and the ecclesiastical hierarchy, with members from other laical organizations and inside the association (ecclesiastical advisers and laics).

I depart here from the hypothesis that, to the middle of the xx century, the profound social differences that characterized the argentinian society were reproduced and naturalized in the Church, per both, ecclesiasticals and laics. This acquires particular implications for the operation of the one association self-styled laborer as the JOC, if it goes attached to an identification of the manual worker as a suspected being and with limited compression capacities. Anyway, this visions of intellectual and social inferiority, accepted uncritically by the jocists, coexisted with self representations of moral superiority respect to the elites questioned by their selfishness and hypocrisy, what contributed to deepen the contrasts of classes and the social distances inside the Church.

KEY WORDS: JOC- class- Church- Argentina- representations- worker

$$
\begin{array}{ll}
\text { Recibido/Received } & \text { 03-07-2012 } \\
\text { Aceptado/Accepted } & \text { 09-09-2014 }
\end{array}
$$

\section{INTRODUCCIÓN}

Luego de la Primera Guerra Mundial, Argentina experimentó una serie de modificaciones en su estructura económica y social que llevó al mejoramiento material de vastas porciones de la sociedad, entre ellas parte de la clase obrera. De todas maneras, el ascenso social de amplios sectores de la población no llegó a borrar las tensiones sociales que se manifestaban en la sociedad, evidenciadas en testimonios contemporáneos, en la prensa de la época y presentes también en los recuerdos.

En la Argentina de entreguerras no existía una noción genérica de trabajador, en el sentido que las divisiones laborales entre ocupación manual, administrativa y profesional eran muy marcadas. Respecto a la primera, el obrero era sinónimo del asalariado dedicado al trabajo manual y poco instruido, diferente del empleado de oficina o comercio que desempeñaba tareas no necesariamente relacionadas con la fuerza física, y de los comerciantes, industriales y profesionales, dueños de capitales materiales o intelectuales, todos ellos identificados como la clase media. ${ }^{3}$ En la prensa se representaba iconográficamente al obrero con músculos prominentes y con vestimenta e instrumentos de trabajo relacionados con las actividades manuales (mameluco o musculosa, boina o sombrero, alpargatas, herramientas en las manos) con un fondo fabril de humeantes chimeneas. ${ }^{4}$ Cabe

\footnotetext{
${ }^{3}$ Véase discurso de Perón en la Asociación Mutualista Moreno en agosto de 1944 en diario Los Principios, 6 de agosto de 1944, p. 1. Acerca de la emergencia de la clase media como identidad durante el peronismo consúltese Adamovsky, E. 2012 [2009]. Historia de la clase media argentina: 239-326. Buenos Aires: Planeta.

${ }^{4}$ Los Principios, 2 de mayo de 1949, p. 2; periódico Juventud Obrera, número 4, agosto de 1943. Cito como ejemplo las publicidades en los diarios de diversas empresas con motivo del $1^{\circ}$ de mayo: diarios El País, 1 de mayo de 1941, p. 5; Los Principios, 1 de mayo de 1946, p. 3.
} 
recalcar que esta identificación del obrero con el trabajo manual iba asociada con limitaciones intelectuales y «la mente simple», ${ }^{5}$ es decir, la ocupación social llevaba implícita una connotación negativa que estaba extendida incluso entre los mismos afectados objeto de la estigmatización. Esto se explica porque en una sociedad de clases las representaciones del sector dominante se imponen como la ideología general para legitimar la relación existente entre ellas y la estructura global de la comunidad. No obstante, dicha situación de dominación es relativa, puesto que no determina de manera lineal el comportamiento, sino que estos discursos coexisten en tensión y disputa con otros con los que tienen que negociar. En otras palabras, las interpelaciones son múltiples y a veces van en sentidos contrarios.

A nivel de las entidades intermedias, dichas diferenciaciones se plasmaban en términos organizativos. Cito el ejemplo del Partido Socialista de Córdoba, que distinguía a representantes obreros y de los empleados o de las asociaciones católicas que pretendían agrupar cada sector socio ocupacional por separado (Profesionales, Empleadas, Juventud Universitaria Católica, Juventud Obrera Católica, etc.). ${ }^{6}$ Las divisiones tenían sustento y a la vez reforzaban diferencias de clase que creaban distancias sociales que, más allá de una mayor igualación en los hábitos de consumo, eran difíciles de flanquear por los ubicados en las posiciones subalternas.

Precisamente y dentro del ámbito asociativo católico, este trabajo se centra en la Juventud Obrera Católica (JOC), fundada en Argentina en 1940 como una respuesta ante la creciente diversificación socio-ocupacional que no era contemplada satisfactoriamente por otras asociaciones como la Acción Católica Argentina (ACA) o los Círculos de Obreros (CCOO). Al igual que las demás organizaciones laicales, la JOC contaba con asesores eclesiásticos como guías espirituales, no necesariamente en exclusividad. Su finalidad era la recristianización de una clase obrera considerada alejada de la Iglesia por el comunismo, a través del apostolado diario de militantes obreros en sus ámbitos cotidianos, como la calle, la fábrica, el taller o el sindicato. El método de trabajo significaba un cambio sustancial desde la perspectiva laical, ya que el análisis partía de la

\footnotetext{
${ }^{5}$ Entre los poderes públicos menciono como ejemplo las palabras de Miguel Rojas de Villafañe, Jefe de Conciliación del Departamento Provincial del Trabajo en Córdoba acerca de las «limitadas capacidades de los obreros...para defender con inteligencia los intereses del personal que representa». Dentro del ámbito católico, las apreciaciones de la Junta de Gobierno de los Círculos de Obreros (CCOO) acerca de la «mentalidad poco compleja» de los obreros y la advertencia en la revista católica Criterio que ciertas telenovelas podían generar «sugestiones malsanas» en las mentes de la «gente simple». Archivo de Gobierno de la Provincia de Córdoba, Serie Gobierno, 1942, tomo 21, p. 228; carta de la Junta de Gobierno de los CCOO al presidente del Círculo de Obreros de Córdoba, 22 de junio de 1940; Caimari, L. 1995. Perón y la Iglesia Católica. Religión, Estado y sociedad en la Argentina (19431955): 295. Buenos Aires: Ariel, respectivamente.
}

${ }^{6}$ Diario Córdoba, 12 de septiembre de 1947, p. 3. 
observación directa del entorno, sin directivas a priori, y se traducía en una mayor autonomía de la estructura eclesiástica, a diferencia de los procedimientos de la ACA donde la formación precedía e impulsaba a la acción. ${ }^{7}$ La JOC también constituía una ruptura con los Círculos en cuanto al enfoque de formación que abarcaba todos los aspectos de la vida del socio.

Parto de la hipótesis que las distancias sociales que marcaron la sociedad argentina de mediados de siglo xx y algunas caracterizaciones que las clases dominantes y trabajadoras construyeron de ellas mismas y de las demás, fueron naturalizadas y reforzadas en el interior de la Iglesia por sus miembros, tanto eclesiásticos como laicos. ${ }^{8}$ La adopción por parte del catolicismo de la imagen negativa del obrero sostenida por los sectores dominantes no constituye una novedad, ${ }^{9}$ pero para el funcionamiento de una asociación laical como la Juventud Obrera Católica adquiere particulares implicancias si en el interior de la Iglesia va unido a una identificación del obrero como alguien potencialmente peligroso y con cuestionadas capacidades intelectuales. Dicha situación influyó en la definición de posiciones de poder y en las dinámicas de relación entre eclesiásticos y laicos y entre los mismos laicos de asociaciones de apostolado que se autorrepresentaban y eran definidas por la Iglesia como distintivas de determinado sector social. Reconstruirlas puede servir para entender desde una perspectiva sociocultural la experiencia jocista, a la vez atravesada por una cultura clasista que resaltaba la superioridad moral de los sectores trabajadores en contraposición a la corrupción y superficialidad endilgada a las demás clases sociales.

En términos analíticos, el artículo sigue el trabajo de Matthew Karush referente a la influencia en el periodo de entreguerras de la cultura masiva (radio, cine y música) para la elaboración de una oposición binaria en clave moral entre los trabajadores y las clases altas y como generadora de imágenes polarizantes de fuerte contenido clasista, de las que el peronismo se valió y fortaleció. ${ }^{10}$ Aquí la categoría de clase no aparece vinculada exclusivamente al antagonismo basado en la desigualdad de posiciones en el sistema de producción, sino que es utilizada de manera novedosa para pensar fenómenos culturales y políticos. El enfoque de este autor se detiene en el análisis de las tensiones sociales

\footnotetext{
${ }^{7}$ Acerca de la estructura y la organización de la ACA argentina durante su primera década de existencia consúltese Blanco, J. 2008. Modernidad conservadora y cultura política. La Acción Católica Argentina (1931-1941): Córdoba: Ferreyra Editor.

${ }^{8}$ Considero a la Iglesia como un sistema de circulación centralizado y jerarquizado por el cuerpo eclesiástico, pero a la vez extendido por la presencia de un desarrollado conjunto escolar y un complejo de congregaciones y movimientos laicales, es decir como un espacio no circunscripto a los eclesiásticos.

${ }^{9}$ Sobre el conflicto de clases en la primera posguerra y las conexiones entre los sectores propietarios y una incipiente nueva derecha católica y autoritaria, véase Rapalo, E. 2012. Patrones y obreros. La ofensiva de la clase propietaria, 1918-1930: Buenos Aires: Siglo XXI.

${ }^{10}$ Karush, M. 2013. Cultura de clase. Radio y cine en la creación de una Argentina dividida (19201946): Buenos Aires: Arielz
} 
expresadas en el territorio cultural y en facetas de la vida cotidiana como los consumos culturales populares. Los sectores subalternos legitimaron esta conflictividad a través de la apelación a las características morales de las distintas clases y del posicionamiento moralmente superior de ellos en la escala social.

Al respecto, en el prólogo Ezequiel Adamovsky brinda una buena síntesis de la tesis de Karush:

Karush no...[afirma] la persistencia de una cultura obrera que se expresaba en los términos propios de la tradición de izquierda, sino echando luz sobre un tipo de antagonismo «populista», en el que los deseos de bienestar, consumo y ascenso social conviven sin contradicción inevitable con la hostilidad hacia los ricos. Dicho en otros términos, un tipo de clasismo que se expresaba a través de una identidad «popular» más integradora que la obrerista y que no implicaba un rechazo de raíz de la sociedad capitalista (lo que no le impedía generar un profundo clivaje social de efectos bien reales).» ${ }^{11}$

El trabajo está estructurado conforme a las vinculaciones reales y simbólicas entre la jerarquía eclesiástica y la JOC argentina y entre esta y su par internacional, las cuales son interpretadas de acuerdo con el lugar que ocupaba la Juventud Obrera en la agenda del Episcopado. A continuación se analizan los integrantes de la asociación (laicos y asesores) y las relaciones y representaciones mutuas. Por último, las imágenes que tanto asesores eclesiásticos de la JOC como jocistas construyeron de otras asociaciones de apostolado consideradas de clase media y la incidencia de las mismas en las dinámicas de interacción. Las principales fuentes utilizadas refieren al periódico de la asociación, Juventud Obrera, a la revista editada por los asesores jocistas y sacerdotes cercanos a la JOC, Notas de Pastoral Jocista (NPJ), y a testimonios de antiguos miembros de Córdoba y Buenos Aires.

\section{VinCULACIONES DE LA ASOCIACIÓN CON El EPISCOPADO Y LA JOC INTERNACIONAL}

La JOC argentina era percibida tanto por sus militantes como por sus asesores como un movimiento permitido pero no promovido por la jerarquía eclesiástica, ${ }^{12}$ fundamentalmente porque se trataba de una organización de origen extranjero y porque su prédica reflejaba un compromiso con los pobres, a quienes se temía por las supuestas consecuencias sociales de sus acciones. ${ }^{13}$ De acuerdo con el testimonio del antiguo dirigente jocista bonaerense Alfredo Di Pacce «la jerarquía toleraba a la JOC pero no le daba ningún espacio más. Entonces había párrocos que decían: 'Y, le voy a consultar al obispo [para crear una sección de JOC],' lo

\footnotetext{
${ }^{11}$ Adamovsky, E. 2013. «Prólogo» en Karush, M.: 15.

${ }^{12}$ Entrevistas al ex dirigente jocista Alfredo Di Pacce y a los ex asesores jocistas Lucio Gera y Domingo Basso. Caimari también sostiene la diferencia de apoyo del Episcopado en beneficio de los Círculos. Caimari, L. 1995: 91.

${ }^{13}$ Testimonios de los ex dirigentes jocistas Francisco Pérez y Efraín Guzmán.
} 
cual quería decir que no». La impresión de los sacerdotes entrevistados es que los obispos controlaban a los asesores jocistas con el objetivo de que acataran totalmente las directivas de la jerarquía, pretensión considerada ilusoria de acuerdo a la inserción de la Juventud Obrera Católica en un ámbito conflictivo que exigía el compromiso social y político. ${ }^{14}$ En este sentido, el apoyo de los obispos Emilio Di Pasquo y Enrique Rau, que se desempeñaron como asesores nacionales de la JOC, constituyó una excepción. En lo que respecta a la jerarquía de Córdoba, el arzobispo Fermín Lafitte fue uno de los primeros en estimular a la asociación en la diócesis y, gracias a las gestiones del asesor local Enrique Angelelli, concretó su funcionamiento federal y seccional por medio del nombramiento de asesores.$^{15} \mathrm{De}$ todas maneras, fue percibido por los jocistas como alguien distante de la grey, que entablaba una relación protocolar con la JOC. El obispo auxiliar Ramón Castellano es evocado como más cercano y accesible a los fieles, pero tampoco se lo presenta muy comprometido en reclamos y denuncias, a diferencia de Angelelli. ${ }^{16}$

Los ex asesores jocistas Lucio Gera (Buenos Aires) y Domingo Basso (Córdoba) recuerdan a los cardenales Santiago Luis Copello y Antonio Caggiano como los principales opositores nacionales a la JOC. El primero se negó a que dicha asociación se incorporara, al igual que en otros países, como quinta rama de la ACA, porque apoyaba en cambio a los CCOO y su versión juvenil, las Vanguardias Obreras Católicas, que competían con la JOC en ser reconocidas por los gobiernos peronistas como entidades representativas de la juventud trabajadora argentina. Respecto a Caggiano, Basso rememora que incentivaba a los seminaristas a concurrir a las asambleas de la Acción Católica, pero no que profundizaran sus conocimientos sobre la JOC. La indiferencia de Caggiano es explicada por estos religiosos debido al origen foráneo de la asociación y porque él había promovido en Argentina a la ACA, y la resguardaba de competencias asociativas laicas. Empero, la Acción Católica también procedía del exterior, aunque como resultado del proceso de romanización; en cambio la JOC había sido fundada por iniciativa personal de un clérigo y con una autonomía que era incompatible con la subordinación absoluta pretendida por el Episcopado. ${ }^{17}$

\footnotetext{
${ }^{14}$ Testimonio del sacerdote (con dispensa papal) Erio Vaudagna. Consúltense palabras del obispo Silvino Martínez en revista Notas de Pastoral Jocista, marzo-abril de 1956, pp. 89 y 91.

${ }^{15}$ Testimonio de Domingo Basso, quien en 1954, a los días de llegar a Córdoba, fue propuesto por Angelelli a Lafitte como asesor federal de la JOC Femenina.

${ }^{16}$ Testimonios de los ex dirigentes jocistas Justa Ledesma, Genaro Murúa, Francisco Pérez, Efraín Guzmán y Francisco Angulo.

${ }^{17} \mathrm{El}$ verticalismo de Caggiano y su molestia por el desarrollo de un apostolado laico independiente de la jerarquía eclesiástica queda evidenciado en su lección del 9 de octubre de 1951 en el Congreso mundial del apostolado de los laicos, donde se refiere a la naturaleza de la Iglesia y de su apostolado y al lugar que ocupan la jerarquía y los laicos, omitiendo la mención de los sacerdotes. Caggiano, A. 1951. Fundamentos doctrinales del Apostolado de los laicos. Lección dada en el Congreso Mundial del Apostolado de los laicos en Roma el 9 de octubre de 1951: 15, 23, 28, 29, 64. Buenos Aires: Junta
} 
La JOC, como otros grupos católicos, necesitaba legitimar sus discursos y acciones en un espacio, la Iglesia, en el que competía con otros actores por asesores, apoyos institucionales y económicos, respaldo a iniciativas sociales y a asociados, etc. La revista de los asesores de la asociación y el periódico Juventud Obrera fueron los principales instrumentos utilizados para concretar dicha finalidad: el aval del Papa a la JOC y la correspondencia entre las ideas jocistas y las encíclicas se mostraban como evidencia de que la interpretación de la asociación era la que más se ajustaba a las máximas eclesiásticas. No obstante, esta apelación a la palabra papal en parte se realizaba por defecto, ante la indiferencia del Episcopado argentino.

El Papa fue adoptado como referente internacional y figura legitimadora del movimiento, a través de la reproducción de sus discursos sobre los obreros en las publicaciones de la JOC. Por el contrario, las menciones a jerarquías nacionales concretas eran prácticamente inexistentes tanto en NPJ como en Juventud Obrera.$^{18}$ De todas maneras, el apoyo del Papa a la JOC tampoco era percibido por sus miembros como constante e incondicional. $\mathrm{Al}$ respecto, las fuentes rescatan la defensa que el fundador de la JOC, el canónigo belga Joseph Cardjin tuvo de su vocación sacerdotal y su identidad obrera mediante la superación de impedimentos políticos externos (capturas durante las guerras mundiales) e internos (la aceptación eclesiástica de su iniciativa apostólica para mejorar la situación de su clase de procedencia, la obrera):

Ya en 1925, varias Secciones [de la JOC] desarrollaron una acción eficaz en Bélgica; y por su parte, la Jerarquía, ante la evidencia de la Acción Católica Obrera, aprobó oficialmente el Movimiento y le dio su Paternal Bendición. ${ }^{19}$

El fundador de la JOC Cardjin intentaba demostrarle al Papa y a la Iglesia que podía ser que esa clase trabajadora que se había apartado de la Iglesia... [¿?] ¿Por qué? Porque el marxismo había tenido mucha influencia en Europa en los trabajadores. Entonces había un rechazo a la religión y la Iglesia. Tan es así que decían que era el opio de los pueblos. -Entonces Cardjin... se larga a esa aventura con los muchachos y entonces logra hacer esa gran revolución..$^{20}$

Central de ACA. Seis meses después reitera la idea del apostolado laico como auxiliar de la jerarquía en la V Semana de la Junta Central de ACA en Buenos Aires.

${ }^{18}$ Caimari afirma que la nueva generación de sacerdotes -como la que escribe en Notas de Pastoral Jocista y dirige espiritualmente a la JOC- apelaba al Papa para ignorar la instancia eclesiástica nacional. Cf. Caimari, L. 1995: 307. Ya sea por debilidad o como parte de una estrategia de desconocimiento, los componentes laicos y eclesiásticos de la JOC invocaron el respaldo de una autoridad superior internacional, en este caso el Papa.

${ }^{19}$ Ganchegui, O., Derudi, N. 1953. Fundamentos de la JOC. Manual para dirigentes y asesores: 289. Buenos Aires. El destacado me pertenece. Cuando habla de la Jerarquía y la «Paternal Bendición» se alude a Pío XI, quien oficializó la JOC en 1925. Probablemente se refiera a la JOC como «Acción Católica Obrera» porque Pío XI la reconoció como rama especializada de la Acción Católica. Boletín Oficial de la Acción Católica Argentina, Año XI, número 229, mayo de 1941, pp. 304-305.

${ }^{20}$ Testimonio del ex dirigente jocista Efraín Guzmán. El destacado me pertenece. 
Así, Cardjin es recordado por los componentes de la JOC argentina como el primero que advirtió a la jerarquía (el Papa) sobre la problemática obrera, proponiéndole una modalidad de apostolado más comprensiva de las subjetividades de los trabajadores que las existentes hasta el momento.

Tanto Juventud Obrera como NPJ informaban sobre la marcha de la JOC en otras latitudes y sobre las últimas alocuciones de Cardjin y la realización de las semanas de estudio y los congresos internacionales. En este punto cabría analizar los aspectos concretos y simbólicos de esta relación con la JOC Internacional y la de otros países. Por un lado, existía un vínculo efectivo a través de traducciones, correspondencia, participación en congresos, actividades internacionales y viajes de asesores y jocistas de un lugar a otro. ${ }^{21}$ Sin embargo, cabe aclarar que la importancia dada por Juventud Obrera y NPJ a la información referente a la JOC Internacional no encuentra paralelo con la situación de otras asociaciones, por ejemplo la ACA, y que esta cobertura ayudaba a sobredimensionar la relación con la misma. También la centralidad de la figura de Cardjin, con sus visitas y mensajes a las JOC de diferentes países, actuó como hilo conductor de todo el movimiento. Sus viajes a la Argentina en su gira por Latinoamérica entre 1946 y 1955, con una convocatoria más que destacada, a nivel simbólico probablemente ayudó a sus miembros a sentirse pertenecientes a un movimiento mundial vigoroso que apoyaba sus expresiones locales, lo cual venía a suplir la tibieza de la jerarquía eclesiástica.

\section{Los asesores jocistas y su oposición a una Iglesia «burguesa y afeminada»}

Cabe aclarar que aquí considero como miembros de la JOC no solo a los laicos sino a sus asesores, por la significación pastoral de dos iniciativas que llevaron a cabo: las Semanas de Asesores de la JOC y NPJ. Las primeras fueron autoconvocatorias sacerdotales para debatir temas de actualidad pastoral, mientras $N P J$ se constituyó en una tribuna innovadora dentro de la Iglesia.

Notas de Pastoral Jocista (1944-1958), en correspondencia con iniciativas similares de otros países ${ }^{22}$ fue una revista de los asesores de la JOC en la que también estaban invitados a participar otros religiosos e incluso laicos, ya que la

${ }^{21}$ Acerca de la concurrencia de asesores a reuniones de la JOC en Costa Rica (1946), Montreal (1947) y Bruselas consúltense Los Principios, 22 de agosto de 1946, p. 4 y 26 de junio de 1947, p. 5; Notas de Pastoral Jocista, mayo-junio de 1954, pp. 61-62. Sobre la visita de la secretaria internacional de la JOC de Bruselas Margarita Fiévez véase La Voz del Interior, 17 de diciembre de 1952, p. 5.

${ }^{22}$ En Bélgica existía una Notes de Pastorale Jociste de los asesores jocistas y había una revista Masses Ouvrieres, editada en París, que fue lanzada durante la Segunda Guerra Mundial por las Editions Ouvriéres pertenecientes a la Jeunesses Ouvrières Chrétiennes y «que alimentó numerosas reflexiones sobre cuestiones teológicas y pastorales del mundo obrero». Ceamanos Llorens, R. 2002. «L'actualité de l'histoire (1951-1960). Historia del movimiento obrero, historia social». Hispania 210: 303-304; Notas de Pastoral Jocista, septiembre-diciembre de 1950, p. 47 y mayo-junio de 1953, p. 24.

Hispania Sacra, LXVII

135, enero-junio 2015, 339-360, ISSN: 0018-215X, doi: 10.3989/hs.2015.010 
intención era convocar al diálogo y expresar la problemática sacerdotal. De todas maneras, sus interlocutores eran los eclesiásticos y su enfoque eminentemente pastoral. En los círculos sacerdotales, contaba con gran prestigio y era percibida como progresista, dado que fue la primera publicación que realizó planteos críticos sobre la práctica eclesiástica y el lugar que debía cumplir el laicado en la Iglesia, pidiendo renovaciones que luego el Concilio Vaticano II iba a concretar. ${ }^{23}$

Los religiosos cercanos a la JOC partían del diagnóstico de la poderosa presencia de un catolicismo de elite en Argentina, donde en términos generales la fe católica era débil, a pesar de que el $90 \%$ de la población se reconociera perteneciente a esta religión. Las razones principales de la falta de gravitación social de la Iglesia se originaban en la conformación de un cristianismo cerrado e individualista, cercano a las clases poderosas, con obras inadaptadas en el tiempo y reducidas a determinados grupos. ${ }^{24} \mathrm{La}$ Iglesia sostenía una estructura «burguesa y afeminada» reproducida por la parroquia, que producía que los hombres, entre ellos los obreros, no quisieran entrar en ella. ${ }^{25}$ Ambos adjetivos parecieran relacionarse con la tibieza, la falta de compromiso pastoral y laical sincero, la debilidad y la preeminencia de las actividades caritativas y de culto, comúnmente desarrolladas por mujeres de sectores acomodados. En contraposición, se proponía una Iglesia viril -por la asociación tradicional entre la masculinidad y lo público-, conquistadora de espacios y de almas, en definitiva, militante.

Para estos integrantes del clero, algunos de los factores que contribuían a la vivencia externa del cristianismo se referían a los métodos de enseñanza y de comunicación del Evangelio por parte de los integrantes de la Iglesia. Tampoco existía un verdadero espíritu misionero entre los laicos, ya que quienes rodeaban al sacerdote conformaban un círculo preferencial caracterizado por su individualismo religioso y que «...con el pueblo no tienen ni buscan tener contacto positivo». ${ }^{26}$ Eran los predilectos del párroco, en detrimento de otros grupos como la JOC, a manera de hijos legítimos e ilegítimos en la Iglesia:

En esa porción del reino de Dios, que es la Parroquia, no pueden existir «los niños bien», por el apellido, el dinero u otro factor, para quienes las puertas de la Parroquia están siempre abiertas. Todos, deben encontrar en la Parroquia el hogar y en el Párroco un corazón paterno. ${ }^{27}$

${ }^{23}$ Entrevistas a Alfredo Di Pacce, Erio Vaudagna y al presbítero Nelson Dellaferrera.

${ }^{24}$ Notas de Pastoral Jocista, marzo-abril de 1956, pp. 69 y 120; marzo-abril de 1957, p. 33; mayojunio de 1958 , p. 5.

${ }^{25}$ Osvaldo Ganchegui, Antonio González y Alfredo Trusso y Manuel Mercader en Notas de Pastoral Jocista, mayo-junio de 1956, pp. 11-14; marzo-abril de 1956, p. 70; marzo-abril de 1956, pp. 68-69, respectivamente.

${ }^{26}$ Notas de Pastoral Jocista, mayo-agosto de 1951, p. 31.

${ }^{27}$ Notas de Pastoral Jocista julio-agosto de 1954, p. 28. Si bien no se la menciona, la alusión a la Acción Católica es clara. 
Por otro lado, la aceptación y el aval efectivo del párroco a la Juventud Obrera Católica se tornaba difícil porque la atención a la misma (reuniones, actos, visitas, etc.) demandaba considerable atención y tiempo. ${ }^{28}$ También según la percepción de estos curas, dentro del universo católico estaba instalada la opinión de que la JOC dividía a las parroquias y creaba recelos y animosidades, aunque los sacerdotes redactores de NPJ explicaban que este preconcepto se basaba en las falencias formativas y de mentalidad del clero.

En $N P J$ se afirmaba que la JOC era muy resistida por los curas parroquiales, quienes aducían desconocimiento de la obra y falta de tiempo y de sentido para promoverla, pese a que, según Angelelli, la gran mayoría de ellos se hallaba dispuesto a impulsar y atender otras asociaciones laicas. ${ }^{29}$ Puntualmente en el caso de la predicación evangélica para los obreros, el cura solía partir de lo abstracto para explicar situaciones cotidianas, pero terminaba hablando un idioma ininteligible. Según $N P J$, la ausencia de conciencia social del sacerdote y su incomprensión de la realidad -sobre todo la del trabajador- que conducía a la indiferencia religiosa de la población, se debía a la formación recibida en los seminarios, caracterizada de ficticia, teórica, deficiente, anticuada y mediocre..$^{30}$ Debido a esas carencias y a la falta de visión realista, la sociedad -incluidos los mismos miembros de la JOC, tenía una imagen negativa de los sacerdotes, a quienes atribuían actitudes paternalistas. Los eclesiásticos tampoco estaban dispuestos a fomentar la JOC por representaciones de clase que los llevaban a considerar a sus miembros como intelectualmente inferiores. ${ }^{31}$

\section{REPRESENTACIONES MUTUAS Y DINÁMICAS DE INTERACCIÓN ENTRE JOCISTAS Y ASESORES}

El replanteo que realizaron los asesores sobre el modo de relacionarse con la sociedad partía de la reflexión constante acerca de las asociaciones de las que eran parte cumpliendo esa función. Ellos visualizaron una situación religiosa en

\footnotetext{
${ }^{28}$ Testimonios del ex dirigente jocista Genaro Murúa y del dominico Domingo Basso.

${ }^{29}$ Notas de Pastoral Jocista, mayo-agosto de 1951, p. 11; marzo-abril de 1954, p. 15; julio-agosto de 1954, p. 34; mayo-junio de 1956, pp. 11-12; julio-diciembre de 1958, p. 120. La JOC de Chile también padecía la carencia de asesores. Notas de Pastoral Jocista, noviembre-diciembre de 1956, p. 32. Según Omar Acha, la falta crónica de asesores era un problema que también sufría la ACA, aunque en este caso habría que reconocer las mayores demandas que ella exigía del párroco como asesor ante la multiplicidad de ramas.

${ }^{30}$ Osvaldo Ganchegui en Notas de Pastoral Jocista, mayo-junio de 1956, p. 14; septiembre-octubre de 1954, p. 60; Alfredo Trusso y Miguel Ramondetti en julio-agosto de 1955, p. 29; mayo-junio de 1954, p. 52; septiembre-octubre de 1955, p. 12; julio-diciembre de 1958, pp. 39-40; septiembre-octubre de 1955, pp. 28 y 30; marzo-abril de 1956, p. 128.

${ }^{31}$ Notas de Pastoral Jocista, marzo-abril de 1956, pp. 116 y 127; julio-diciembre de 1958, pp. 119 y 120 .
}

Hispania Sacra, LXVII

135, enero-junio 2015, 339-360, ISSN: 0018-215X, doi: 10.3989/hs.2015.010 
la que la gran mayoría de la población era indiferente a la Iglesia y a la palabra del cura, con una prédica y atención restringidas a los sectores de mayores recursos, poder e influencias. La Iglesia era una institución que marginaba a los trabajadores y a los movimientos que los incluían, como una extensión de la representación que los grupos dominantes tenían del obrero en la sociedad argentina de la primera mitad del siglo xx.

En $N P J$ y de acuerdo a la finalidad propuesta por la JOC, se hacía una distinción entre obrero y obrero de masa. El primero era el que trabajaba aislado - probablemente ocupado en actividades artesanales- en contraposición al segundo, que, inserto en un ambiente fabril, podía influir con su prédica y ejemplo entre sus pares. Empero, se reconocía que este último se hallaba limitado a ejercer influencia sobre todos sus compañeros, debido a una distancia mutua para con otros sectores sociales alimentada por el resentimiento y la envidia de clase: «...el obrero no abre su corazón al empleado, que habiendo salido de la clase obrera, aspira a llegar a la clase más alta, con humos de distinción y con pretensiones de más inteligente. $\gg^{32} \mathrm{El}$ hecho de que a cada grupo social se le endilgara una identidad propia indiscutible, tenía consecuencias apostólicas en cuanto a la caracterización psicológica de los miembros. Así, los asesores pensaban para la JOC métodos o formas de estudio acordes con una denominada «mentalidad obrera», que era definida por los mismos militantes como el resultado de una existencia llena de sufrimientos y esfuerzos por tener que trabajar desde niño o muy joven en una labor seguramente no gratificante. Esas mismas experiencias creaban un espíritu de solidaridad y de lucha por la defensa y mejoramiento de su clase, la obrera. ${ }^{33} \mathrm{El}$ contacto temprano con las responsabilidades de la vida adulta hacía suponer que el obrero tenía escaso tiempo para leer e instruirse, en un ambiente poco propicio. Por lo tanto, desde la formación había que abandonar la teología especulativa y adaptarse a los saberes experienciales y a las competencias concretas de la vida cotidiana de los trabajadores. ${ }^{34}$ Hay que reconocer que la formación insuficiente para aprehender la teología católica por parte de los jocistas constituye un dato objetivo, sin embargo, algunos testimonios de $N P J$ en este punto evidencian una carga negativa no exenta de conmiseración y paternalismo: menosprecian la cultura del saber cotidiano, subestimando la aptitud intelectual de los trabajadores y confundiendo conocimiento vivencial con «mentalidad sencilla» y con restricciones naturales para el aprendizaje. Así, acerca de la formación espiritual de los militantes, los mismos asesores jocistas decían lo siguiente:

\footnotetext{
${ }^{32}$ Notas de Pastoral Jocista, mayo-junio de 1949, pp. 12-14.

${ }^{33}$ Testimonio del ex dirigente jocista Efraín Guzmán.

${ }^{34}$ Palabras de Cardjin en Notas de Pastoral Jocista, julio-agosto de 1953, pp. 12-14; septiembreoctubre de 1954, p. 60; Ganchegui, O., Derudi, N. 1953: 161.
} 
...hagámoles [sic] contar su pequeña historia de trabajadores...

Tener paciencia enorme para saber el resultado. En los comienzos, tomar a los muchachos como son: hacerlos más «humanos», o simplemente, civilizarlos. Esto es ya preparar el terreno para una acción más espiritual..$^{35}$

Es probable que dichas ideas influyeran en la propia representación de los miembros de la JOC, repercutiendo en su falta de relación con grupos considerados de clase media y alta, como la Acción Católica. Las entrevistas evidencian automarginación y sentimiento de inferioridad intelectual y social que hasta el día de hoy subsiste en algunos antiguos jocistas y que probablemente fue fomentado por gestos y prácticas de asesores eclesiásticos. Así, encontraban fuera de sus ambiciones y posibilidades el formar parte de la Juventud de la ACA (JAC), el ingresar a la universidad o realizar trabajos calificados que requerían «buena presencia» y cierto tipo de vestimenta. ${ }^{36} \mathrm{Al}$ respecto, el testimonio de la jocista Livia Castro ilustra esta autodiscriminación obrera, al aclarar que el asesor José Echevarría «se bajaba al nivel del trabajador» y el dominico Domingo Basso «se adaptaba más a nosotros por el nivel intelectual», mientras los otros religiosos «se mantenían un poco más arriba», e incluso algunos se orientaban a las socias de mayor formación.

Según Alfredo Di Pacce, los más permeables a fundar la JOC fueron los sacerdotes jóvenes, egresados recientemente del seminario, que tenían interés por desarrollar en la parroquia alguna actividad social -en esa época sinónimo de «progresismo»-. Los de mayor edad eran más reacios y objetaban que los obreros hacían ruido y les ensuciaban la parroquia, comportamiento que provocaba la queja de las señoras de la Acción Católica, ${ }^{37}$ seguramente por juzgarlo inadecuado de acuerdo a sus parámetros de urbanidad. Ahora bien, si consideramos la identidad laboral y etaria a la que apuntaba la asociación, ¿qué les habrá generado más empatía a los laicos de los asesores, su corta edad o su extracción social y experiencia popular? Si pensáramos que el factor etario constituyó un elemento central de atracción, estaríamos adscribiendo al ficticio presupuesto de la Acción Católica -que violenta el espíritu de la JOC-, que considera que las personas de la misma edad tienen vivencias similares. Probablemente la comprensión de clase por parte de estos sacerdotes, es decir, el conocimiento de las carencias y los problemas de los obreros debido al origen y pertenencia pasada al sector trabajador.

De todas maneras, el hecho de que la JOC existiera a nivel parroquial podía significar solamente que las figuras eclesiásticas la toleraran, pero no que la apoyaran entusiastamente, como lo demuestra el caso de las habituales ausencias

${ }^{35}$ Notas de Pastoral Jocista, mayo-junio de 1949, p. 15 y julio-agosto de 1949, p. 25 . El destacado me pertenece.

${ }^{36}$ Testimonios de los ex dirigentes jocistas Francisco Pérez, Efraín Guzmán y Mario Bravo.

${ }^{37}$ Estas impresiones coinciden con las de las Notas de Pastoral Jocista y con el perfil etario y socioeconómico del grupo redactor de la misma y de los asesores de la JOC en Córdoba. 
del asesor en las reuniones de las secciones. Justa Ledesma recuerda que en la céntrica parroquia del Pilar, en la ciudad de Córdoba, los socios lograron el respaldo del ayudante del párroco, el teniente cura Manuel Andreatta, a pesar de las reticencias del titular parroquial. Usualmente los seminaristas eran encomendados para ocupar la dirección espiritual de las secciones. ${ }^{38}$

A la hora de aceptar dirigir un grupo jocista, en los religiosos influían factores como la edad, los años de ordenación, la ubicación de la parroquia, pero también pesaban representaciones de clase que encuadraban al obrero en una persona poco confiable y hasta peligrosa, idea que se profundizó luego del 17 de octubre de 1945 entre los sectores identificados con el antiperonismo. ${ }^{39}$ Cabe aclarar que esta visión convivía con otra, alimentada en los discursos de Perón y observable en algunas películas y radioteatros del periodo, que representaba a los jóvenes de los sectores humildes como la encarnación de la verdadera moral. ${ }^{40}$

Entre los asesores de la JOC también podemos encontrar huellas de la visión cautelosa hacia los trabajadores, quienes parecían formar «un mundo aparte», al que ellos ya no pertenecían:

A mí el obrero no me asustaba. De chico había vivido toda la vida entre obreros y siendo fraile también.

Mis padres eran obreros, mis padres eran trabajadores. Toda mi niñez, mi infancia y mi juventud estuve en ese ambiente. Mis compañeros del secundario más bien eran... obreros o [de] una pequeña clase media bajita.... Era un poco mi mundo. Además le tenía afecto a ese mundo, no?. ${ }^{41}$

Es cierto que muchos de los religiosos cercanos a la JOC compartían un origen de bajos ingresos y tenían un conocimiento personal de ese ambiente, pero si bien provenían de los sectores trabajadores, ya no pertenecían a ellos, porque se había producido su ascenso social a través de la formación sacerdotal.

\footnotetext{
${ }^{38}$ Testimonios de los ex dirigentes y militantes jocistas Oscar Morandini, Francisco Angulo, Dardo Alfaro, Américo Cáceres, Luis Pérez Gaudio y Efraín Guzmán.

${ }^{39}$ Para los socialistas y los comunistas los participantes del 17 y 18 de octubre no eran auténticos obreros, sino «maleantes y hampones» $\mathrm{y}$ «elementos desclasados dirigidos por matones a sueldo». Véase Del Campo, H. 1983. Sindicalismo y peronismo. Los comienzos de un vínculo perdurable: 230 Buenos Aires: Clacso; diario Córdoba, 20 de octubre de 1945, p. 5; Los Principios, 20 de octubre de 1945 , p. 3 .

${ }^{40}$ Cosse, I. 2006. Estigmas de nacimiento. Peronismo y orden familiar 1946-1955: 39-40. Buenos Aires: FCE-Universidad de San Andrés; Gené, M. 2005. Un mundo feliz. Imágenes de los trabajadores en el primer peronismo. 1946-1955: Buenos Aires: Fondo de Cultura Económica; Karush, M. 2013.

${ }^{41}$ Testimonios de Domingo Basso y Lucio Gera, respectivamente. El destacado me pertenece. Todos los religiosos entrevistados vinculados a la JOC (Nelson Dellaferrera, Lucio Gera, Domingo Basso y Erio Vaudagna) provenían de familias de escasos recursos económicos, con antecedentes inmigratorios recientes y que en su niñez y juventud habían sufrido penurias de índole material.
} 
Ahora bien, ¿de quiénes está hablando la JOC cuando interpela a «los obreros» para la recristianización de los lugares de trabajo? Como ya indiqué, la concepción del obrero se basaba en diferenciaciones sociales tomadas como naturales, que eran promovidas y reafirmadas por los asesores eclesiásticos y desde el mismo periódico Juventud Obrera. La publicación hacía una interpelación al trabajador manual como sinónimo de obrero, quien era el único representado en fotografías o dibujos en su labor diaria. ${ }^{42}$

En términos sociológicos, desde las páginas de Juventud Obrera aparecía la necesidad de defender la posición y la función social de los obreros, ya que se aclaraba que estos no tenían porqué sentir vergüenza de su condición, por más que muchos consideraban que ser empleado significaba pertenecer a una categoría superior. En un momento en que los estándares de vida de los sectores trabajadores estaba mejorando considerablemente como resultado de las políticas redistributivas peronistas, la JOC no promovía la búsqueda del ascenso social individual o colectivo; más bien alentaba un conformismo que ocultaba «orgullo de clase», en términos de Karush. Asimismo, se mencionaba el origen de algunos Papas y del mismo Jesucristo como demostración de la contribución hecha por este sector productivo a la humanidad, y por ende de una capacidad intelectual, que, dada las reiteradas aclaraciones de la fuente, nos confirma que en esa época era puesta en duda. ${ }^{43}$ Por último, se presentaba como vocación una posición social derivada de las relaciones sociales de producción. Al igual que Jesús, todos llevamos nuestras cruces en la vida, y las de los obreros son el sufrimiento y el sacrificio, las cuales debían ser aceptadas con satisfacción. En relación a la figura del Cristo Obrero, Justa Ledesma resaltaba el oficio carpintero de Jesús como justificativo de su posición social: «Porque fue obrero. Era carpintero Jesús. Así que nunca hicimos mella de que nosotras fuéramos obreras (...) de que nosotras nos rebajáramos porque éramos obreras. Cristo y la madre de Jesús daban el ejemplo». ${ }^{44}$

\footnotetext{
42 Juventud Obrera, número 120, julio de 1952. Algunos ejemplos iconográficos en Juventud Obrera, número 36, agosto de 1946; número 4, agosto de 1943; número 5, septiembre de 1943; número 19, diciembre de 1944, número 24 , junio de 1945 ; número 26 , agosto de 1945 ; número 38 , octubre de 1946 y número 43, $1^{\circ}$ de febrero de 1947.

${ }_{43}^{43}$ Ejemplos en Juventud Obrera, número 26, agosto de 1945; número 45, 1º de marzo de 1947; número 46, 15 de marzo de 1947; número 47, $1^{\circ}$ de abril de 1947 y número 120, julio de 1952.

${ }^{44}$ También se encuentran ejemplos en Juventud Obrera, número 1, mayo de 1943; número 26, agosto de 1945, p. 5; número 45, $1^{\circ}$ de marzo de 1947, p. 4; número 46, 15 de marzo de 1947, p. 2; número $47,1^{\circ}$ de abril de 1947 , p. 8; número 120, julio de 1952. Cabe aclarar que los Círculos de Obreros ya habían recuperado el aspecto obrero de Jesús, aunque con la JOC esta figura cobrará una centralidad insoslayable desde sus años fundacionales. Sin embargo, la adopción de la persona de Jesús como modelo no fue privativa de la JOC y los Círculos, dado que ciertas características de su vida además serán exaltadas u omitidas por otras asociaciones católicas de acuerdo a los distintos sectores sociales e intereses representados. Así, por ejemplo, la Juventud de la Acción Católica reivindicaba la figura de Cristo pero Rey, aquel Cristo Joven que se preparó durante su adolescencia y juventud para llegar a ser líder.
} 
La adopción de la imagen de Jesús en su faceta obrera operará como legitimadora de la asociación en el interior de la Iglesia y como dadora de valor social de la actividad laboral del jocista:

Junto al Altar del Sacrificio Redentor, el Altar del Trabajo Cristiano. Y en torno a la imagen de Cristo Obrero, los instrumentos de trabajo. El yunque y el martillo. La máquina de coser y el torno eléctrico. Altares también ellos donde el jocista inmola, en unión de Cristo Obrero, el sacrificio redentor de su trabajo diario. ${ }^{45}$

Los entrevistados reconocen en Cristo Obrero un testimonio de vida y a su persona como ejemplo a seguir en sus ámbitos de trabajo. A nivel discursivo y de las mentalidades se manifiesta una asimilación con la vida de Jesús en cuanto a la actividad laboral, el compromiso y hasta el sufrimiento por la salvación de los otros. Sin embargo, también se puede pensar que la identificación con Cristo Obrero y el reconocimiento de los padecimientos vividos pudieron haber alimentado la construcción de una identidad ligada a características que en la cultura jocista cobraban un sentido positivo, como la solidaridad, el sufrimiento, la humildad, el compromiso, la vocación de servicio, que se contraponían con los valores endilgados a los sectores propietarios o más pudientes (incluidos los católicos) que veremos en el próximo apartado: frivolidad, egoísmo, hipocresía, insensatez, identificados como signos de corrupción moral.

En la cultura forjada al calor de la experiencia jocista, el clivaje de clase se torna fundamental. Me refiero a una cultura jocista como un conjunto de valores y formas de percibir el mundo cultivados o fortalecidos durante la militancia en la JOC, que brindan sentido a los comportamientos e influyen en la elaboración de identidades y aspiraciones. Esta cultura jocista es clasista pero no en la perspectiva comunista de lucha contra el sistema capitalista y de búsqueda de la subversión social (la propuesta de la JOC era humanizar el capitalismo para una mayor igualación pero sin cuestionar las diferencias naturales sobre la que la Iglesia basaba su propuesta social). En este sentido, es clasista pero fundamentalmente en términos morales, por su identificación de los trabajadores con valores considerados positivos como el sacrificio, la superación, la fortaleza, la autenticidad, la sencillez, etc. La cultura clasista jocista estuvo en tensión con la máxima católica de la armonía social, ya que abonó los antagonismos irresueltos preexistentes con otros sectores sociales, considerados moralmente inferiores por el materialismo individualista y las acciones vacías de espiritualidad, la superficialidad y la corrupción propias del «capitalismo burgués».

\footnotetext{
45 Juventud Obrera, número 4, agosto de 1943.
} 
INFERIORIDAD INTELECTUAL Y SOCIAL/ SUPERIORIDAD MORAL. LA RELACIÓN CON OTRAS ASOCIACIONES DE APOSTOLADO SOCIAL

A principios de los años 40, el asociacionismo social católico concentrado en atender las demandas y necesidades de los sectores trabajadores ocupaba un espacio destacado en la Iglesia. A modo de ejemplo puedo mencionar la ACA, los CCOO, la JOC, los Vicentinos y los Josefinos. Con excepción de la primera, las demás constituyeron propuestas asociativas particulares que tuvieron una relación relativamente autónoma con la iniciativa de origen papal ${ }^{46} \mathrm{~A}$ continuación haré hincapié en la vinculación de la JOC con la Acción Católica, puesto que en Argentina la primera surgió por iniciativa de la segunda como una respuesta organizativa laical que flexibilizara su estructura etaria y de género a fin de contemplar las diferentes realidades socio-ocupacionales.

Las críticas de la JOC a la ACA y los CCOO provenían tanto de los asesores como de los militantes. Respecto a los primeros, en $N P J$ y las Semanas los religiosos resaltaban el lugar subalterno otorgado a la JOC en la parroquia:

¿La J.O.C ocupa en el orden parroquial, en las Juntas Parroquiales, el lugar que le corresponde? Quizá muchas veces, si es que ha logrado formar parte de la Junta Parroquial, es considerada por las demás asociaciones en un plano de inferioridad y de conmiseración, haciéndose uso de ella únicamente cuando se trata de trabajo manual y de esfuerzo en la línea del músculo y de la fuerza física, por la sola causa de que los que la componen son obreros. ${ }^{47}$

Estos sacerdotes acusaban a la ACA de ser un instrumento de evangelización de las clases medias cuando, al ser un movimiento oficial, en teoría debería haber actuado por igual con todos los sectores sociales. Por su parte, explicaban la decadencia de los Círculos dada su pretensión de influir entre los trabajadores desde afuera, ya que sus miembros no eran obreros ni tampoco los interpelaban en este aspecto. ${ }^{48}$

En cuanto a los militantes, en la representación que la JOC hacía en su periódico del joven trabajador convergían variables de edad y de género, pero también se patentizaban distancias de clase. La apelación que realizaba era sensible a las diferencias de riqueza y empleo, ya que se reconocía que los jóvenes de

${ }^{46}$ Junta Central de Acción Católica Argentina, Anuario Católico Argentino 1943, Buenos Aires, 1943, p. 211.

${ }^{47}$ Enrique Angelelli en Notas de Pastoral Jocista, julio-agosto de 1954, p. 38.

${ }^{48}$ Notas de Pastoral Jocista, marzo-abril de 1957, p. 29; julio-agosto 1956, p. 15. Estudios recientes relativizan la idea extendida de la composición elitista de los Círculos de Obreros, incluso respecto a sus comisiones directivas. Consúltese Vidal, G. 2012. «Asociacionismo Católico de Córdoba. Composición Social de las Comisiones Directivas del Círculo de Obreros de Córdoba, 1897- 1930» en G. Caretta, I. Zacca (comps.), Derroteros en la construcción de Religiosidades. Sujetos, instituciones y poder en Sudamérica, siglos XVII al Xx: 197-218. Salta: ediciones del CEPIHA-UNSTA-CONICET.

Hispania Sacra, LXVII

135, enero-junio 2015, 339-360, ISSN: 0018-215X, doi: 10.3989/hs.2015.010 
la JOC no experimentaban las mismas realidades que los de la ACA. De este modo, la idea general que identificaba juventud como moratoria social, y que pretendió encarnar la Iglesia a través de la JAC, no se ajustaba a la realidad de los miembros de la JOC. Aquí la diferenciación interna entre Prejocistas (doce a catorce años) y Jocistas (quince a veinticinco) parece más una respuesta a las actividades de los miembros (el muchacho de PREJOC en la escuela de oficios y como aprendiz y el joven con un pleno desempeño en la vida laboral) que a la correspondencia con la adolescencia y la juventud burguesas, respectivamente. En síntesis, la cultura juvenil obrera aparece en el periódico como una subcultura, pero más definida desde la clase que desde la edad.

En los años preparativos de la JOC, el cometido de la ACA era la «preparación del ambiente» (atracción, organización y formación cristiana) entre los obreros de la JAC para que ellos mismos pudieran dirigir una organización separada, es decir que la conformación de la Juventud Obrera dependía en parte de la separación de obreros pertenecientes a la JAC. Ahora bien ¿habrá habido un traspaso de $\operatorname{socios}^{49}$ de la JAC a la JOC o esta se habrá nutrido fundamentalmente de nuevos elementos? Para responder la pregunta tenemos que indagar en la composición ocupacional de los integrantes de la JAC y su sección Aspirantes.

Las estadísticas oficiales de la JAC son escuetas pero pueden orientarnos al respecto. Se trata del Censo profesional de la categoría Efectivos (jóvenes de 16 a 30 años) que,-según la fuente- representaba proporcionalmente a todas las diócesis, realizado entre 1940 y 1943; de este último año solo se tienen registros de algo menos de la sexta parte. Los estudiantes (en su mayoría secundarios) conformaban el $42 \%$, seguidos por los empleados con el $30 \%$, mientras los obreros contabilizaban el 13,3\%, es decir, los sectores estudiantil y los insertos en el mercado laboral representaban una tasa similar. Entre los Aspirantes -con posibilidades de ingresar a la PREJOC-, casi el 90\% tenía entre 12 y 15 años, la mayoría eran estudiantes primarios y secundarios (95\%) y el resto obreros $(5 \%) .^{50}$ Esta baja proporción de trabajadores manuales en las filas de la Juventud de AC probablemente se explica por la identificación social de esa asociación con los sectores medios y medio altos. Al respecto, y pese al rechazo a nivel discursivo de los «pitucos», definidos como quienes repudiaban lo plebeyo, ${ }^{51}$ la JAC reconocía la existencia entre los católicos de

\footnotetext{
${ }^{49}$ Miguel, antiguo jocista de Buenos Aires, reconoce su pasado en la JAC (agradezco al Dr. Jorge Soneira, realizador de dicha entrevista, el acceso a este testimonio). Héctor Sánchez fue miembro de la JAC desde 1940 y en 1945 ayudó a la constitución de una sección jocista en Morón. Bottinelli, L. et al 2001. «La JOC. El retorno de Cristo Obrero» en F. Mallimaci, R. Di Stefano, Roberto (comps.), Religión e imaginario social: 112. Buenos Aires: Manantial.

${ }^{50}$ Asociación de los Jóvenes de la Acción Católica 1943. Memoria y balance presentados por el Consejo Superior a la Quinta Asamblea Federal. Período 1940-1943: 66-68. Argentina.

${ }^{51}$ Franceschi, Gustavo, «Nuestra Juventud», en Criterio, 12 de noviembre de 1942.
} 
un trato desigual con los obreros, que pretendía revertirse con la creación de la JOC. Así, en 1941 la JAC indicaba en su programa general: «Abandonemos todos los procesos mezquinos de control, de recompensas y de fiscalización. No los tratemos [a los obreros] como a niños y colegiales $\gg .{ }^{52}$ Esta especie de tutelaje se asentaba en la ya mencionada subestimación intelectual y social de los trabajadores característica de la sociedad de esa época, representación que asociaciones laicales como la ACA y sus secciones (universitarios, secundarios, profesionales) o derivados (obreros) ayudaban a naturalizar en su retórica y prácticas cotidianas.

Los contactos entre los militantes de ambas asociaciones se reducían a los préstamos de local y las colaboraciones en iniciativas mutuas, como el apoyo en la organización de asambleas o de encuestas nacionales.$^{53}$ La distancia también era percibida como social, y determinaba que los profesionales y los empleados ingresaran a la ACA y los trabajadores menos calificados eligieran la JOC, conforme lo confiesan algunos antiguos militantes jocistas:

Como [que] había una diferencia... La gente de Acción Católica eran aquellos que eran empleados más altos o eran profesionales. Los trabajadores no podían entrar a Acción Católica. No es que los trabajadores no pudiéramos entrar ahí, sino [que] sencillamente... nos automarginábamos.

Los grupos -Juventud Obrera Católica- mirábamos a la Acción Católica como un movimiento que era muy paternalista con nosotros. Nos miraban como «pobrecitos los chicos allá». (...) Nosotros lo percibíamos.

...la miraba [a la JOC] con desprecio la Acción Católica. La Acción Católica ha sido [compuesta por] gente [de clase] media con nariz parada, oligarca, más o menos así ha sido siempre. ${ }^{54}$

${ }^{52}$ Boletín Oficial de la Acción Católica Argentina, Año XI, número 235, noviembre de 1941, p. 276. La cursiva pertenece al original. Omar Acha también resalta que las propuestas de las «damas católicas» de la ACA estaban permeadas por una evidente pertenencia a las clases altas. Asimismo, afirma que a principios de los años 40 la desigualdad de clase en el interior de los círculos de las jóvenes de la asociación era un tema delicado que suscitaba roces. Acha, O. 2011. «Activismo y sociabilidad en las jóvenes de la Acción Católica en la ciudad de Buenos Aires (1930-1945)». Cuadernos de Historia. Serie Economía y Sociedad 12.

${ }^{53}$ Entrevista a Eduardo Luque (perteneciente a la JAC de Córdoba). Los jocistas entrevistados afirmaron que los vínculos con la Acción Católica de Córdoba en general eran prácticamente nulos. Ver ejemplos de eventos compartidos en Boletín del Dirigente de la Asociación de los Jóvenes de la Acción Católica Argentina, Año V, número 50, mayo de 1943, p. 90; Junta Central de Acción Católica Argentina, Anuario Católico Argentino 1947, Buenos Aires, 1947, pp. 212-217 y 228; Anuario Católico Argentino 1941, Buenos Aires, 1941, p. 228; Asociación de los Jóvenes de la Acción Católica, Octava Asamblea Federal, Córdoba, 1955, pp. 16 y 29.

${ }^{54}$ Testimonios de Francisco Pérez, Genaro Murúa y Américo Cáceres, respectivamente. El resaltado me pertenece.

Hispania Sacra, LXVII

135, enero-junio 2015, 339-360, ISSN: 0018-215X, doi: 10.3989/hs.2015.010 
El entrevistado Francisco Pérez pertenecía a la JAC de la parroquia San José (barrio San Martín de la ciudad de Córdoba), pero al unirse a la JOC se desligó de la primera porque sentía distinciones en la composición social de ambas asociaciones, percepción compartida con los jocistas Dardo Alfaro, Oscar Morandini y Livia Castro. Al parecer, esta diferencia de posición social entre los miembros de la ACA y la JOC no era privativa de nuestro país; en Uruguay, por ejemplo, también era advertida por las jocistas en relación con la rama juvenil femenina de la Acción Católica.55

En general los jocistas marcan una distinción entre la autenticidad católica por ellos representada y el aburguesamiento de las otras asociaciones. Las fuentes no distinguen explícitamente al auténtico católico de los otros, pero se lo diferencia del «pituco» y aparece claramente la defensa y superioridad del modelo integral del laico como militante, es decir, aquel que se constituía en paradigma por la retórica empleada y su actividad cotidiana en desmedro del fiel que se limitaba a desfilar en las manifestaciones de fe, el que se pasaba encerrado en la sacristía o la Dama de Beneficencia que, con su labor caritativa desprovista de justicia, solo tranquilizaba su conciencia y se convertía de ese modo en cómplice del capitalismo. También se cuestionaba a los «católicos de nombre» como aquellos patrones que se decían creyentes pero que no aplicaban la máxima cristiana de la justicia social si no eran obligados por la ley. Estas eran críticas hacia determinado tipo de católico claramente permeadas por consideraciones de clase. Así, específicamente en el ámbito social, ante «los tibios» la JOC privilegiaba la justicia a la caridad y la defensa de los derechos del trabajador al paternalismo social que garantizaba el orden. ${ }^{56}$

...Congreso de la Juventud [organizado por la JOC en 1946]...fue la luz que abrió los ojos a los patrones «para que reflejen justicia y caridad», para que vean las miserias del desvalido, para que comprendan y se apiaden de sus sufrimientos, para que los consideren hijos de Dios y no bestias, ni máquinas, que tan igual es el patrón que el último obrero ante los ojos de Dios; para que conviertan sus fábricas y talleres en segundos hogares, en escuelas de honestidad, laboriosidad y caridad, y no en casas de inmoralidad, inconciencias[sic] e irresponsabilidades... ${ }^{57}$

${ }^{55}$ Véase el testimonio de Aurora Buraglio en García Mourelle, L. 2001. «La Juventud Obrera Católica Femenina (JOCF) en Uruguay (1944-1960): su experiencia en el mundo del trabajo» en C. Touris (coord.), Actas de las Segundas Jornadas de Religión y Sociedad en la Argentina Contemporánea y países del Cono Sur (RELIGAR-SUR). Buenos Aires: editorial de la Facultad de Filosofía y Letras Universidad de Buenos Aires (CD-ROM).

${ }^{56}$ Juventud Obrera, número 1, $1^{\circ}$ de mayo de 1943, p. 3; número 5, septiembre de 1943; número 40, diciembre de 1946; número 37, septiembre de 1946; número 38, octubre de 1946, p. 8; número 39, noviembre de 1946; número 33 , mayo de 1946 , p. 2; número 24 , junio de 1945 ; número $41,1^{\circ}$ de enero de 1947; entrevista a Alfredo Di Pacce.

${ }^{57}$ Juventud Obrera, número 37, septiembre de 1946. 
En concordancia con las apelaciones de Perón,${ }^{58}$ aquí aparece una petición pública de que los obreros, por su trabajo honesto y duro, sean reconocidos en su dignidad, respetabilidad y virtuosidad. No obstante, este reclamo esperanzado de igualación social coexistía con el rechazo hacia los sectores propietarios por su codicia e insensibilidad hacia la pobreza y la necesidad ajena. Estos defectos eran aludidos en acusaciones como la de «pulpos capitalistas y especuladores», ${ }^{9}$ que ante la campaña antiinflacionaria peronista de 1946 (conocida como de los sesenta días) no habían dudado en aumentar considerablemente los precios de las mercancías.

Por último, cuando años después Juventud Obrera se quejaba amargamente de que el mayor poder adquisitivo de los trabajadores tenía el efecto no deseado de su relajamiento moral, evidenciado en la dilapidación del dinero en alcohol o juegos de apuestas, estaban aludiendo al valor del ahorro ${ }^{60}$ caro a los sectores medios, pero también denunciando la obnubilación de los obreros por el consumismo y las diversiones sin sentido del materialismo burgués.

\section{Consideraciones FinALES}

Las caracterizaciones naturalizadas, asociadas a determinadas clases sociales y la connotación negativa de lo obrero hechas propias y reproducidas por los mismos asesores eclesiásticos y en parte por los militantes jocistas, repercutía en la dinámica de interacción de la Juventud Obrera Católica en el interior de la Iglesia. Este punto evidenciaba una contradicción intrínseca de la JOC, puesto que precisamente la innovación y la apuesta más fuerte de la asociación radicaban en el apostolado del obrero por el obrero, aunque paradójicamente algunos guías espirituales dudaran de la capacidad de estos laicos para la tarea.

La JOC constituyó un proyecto apostólico que en la Iglesia no recibió el mismo respaldo que otras asociaciones de apostolado social, como la ACA o los CCOO, no solo porque era una experiencia que contaba con pocos años, sino porque era vista como potencialmente peligrosa: desde la perspectiva de los laicos por la procedencia social de sus integrantes, las temáticas tratadas en sus encuentros y Semanas y la integración en sindicatos ideológicamente heterogéneos; a nivel de los asesores por la organización de reuniones sacerdotales independientes de la jerarquía eclesiástica y la publicación de una revista propia, dos ámbitos críticos de la Iglesia que aportaron a la revisión pastoral y a su relación con la sociedad.

\footnotetext{
${ }^{58}$ Para un análisis de la retórica peronista véase Karush, M. 2013:251-266.

${ }^{59}$ Juventud Obrera, número 38, octubre de 1946.

${ }^{60}$ Juventud Obrera, número 119, junio de 1952.
} 
La cúpula eclesiástica argentina tampoco tuvo un proyecto respecto a la clase obrera a nivel de compromiso institucional (como fue con la ACA), en un ámbito donde todavía se manejaba con prácticas conservadoras y paternalistas, que encontraban su fundamento en la idea extendida entre los grupos dominantes de la connotación social, intelectual y moral negativa de los sectores trabajadores. Tal vez por eso no logró consolidarse entre la clase obrera, que siguió mirándola con desconfianza y desprecio, hostilidad que se acentuó después de la participación de los sectores católicos en el golpe de Estado de 1955 que derrocó a Perón.

Es que con el peronismo la ciudadanía social se inauguró en Argentina y los trabajadores irrumpieron como sujetos políticos de relevancia. La gran mayoría de ellos percibieron que Perón estaba llevando a cabo una revolución social que conseguía dignificarlos y hacerlos irremediablemente visibles ante las demás clases sociales. El descanso anual y los días no laborados por accidente o enfermedad remunerados, las jubilaciones y pensiones, las indemnizaciones, la estabilidad laboral, los salarios familiares, la cobertura de salud, etc., alcanzaron el estatus de derechos sociales y permitieron a los asalariados una participación ampliada en la vida social a través del consumo, la vivienda, la educación y la recreación. En la sociedad de masas, estos consumos posibilitaron una igualación social que en cierto sentido sirvió para contrarrestar y atenuar los contrastes clasistas, situación que, como vimos, no se tradujo con el mismo vigor en el interior de la Iglesia argentina.

Las afinidades entre las posiciones y discursos de la JOC y los de Perón en materia social, política y religiosa probablemente influyeron en la impresión favorable de los militantes hacia el peronismo. En general, las antinomias utilizadas tanto por los jocistas como por Perón (auténtico/falso, sacrificio/egoísmo, austeridad/frivolidad) y, dentro de ellas, la apelación a los auténticos sindicatos y obreros, ayudaron a construir al otro en la escala social conforme a parámetros morales. Hacia mediados de siglo, la cultura jocista definida en clave clasista seguramente vino a alimentar entre sus miembros una identidad peronista, también ella deudora y reforzadora de las divisiones sociales.

\section{BIBLIOGRAFÍA}

Acha, O. 2011. «Activismo y sociabilidad en las jóvenes de la Acción Católica en la ciudad de Buenos Aires (1930-1945)». Cuadernos de Historia. Serie Economía y Sociedad 12:11-34.

Adamovsky, E. 2012 [2009]. Historia de la clase media argentina: Buenos Aires: Planeta.

Asociación de los Jóvenes de la Acción Católica 1943. Memoria y balance presentados por el Consejo Superior a la Quinta Asamblea Federal. Período 1940-1943: Argentina. 
Blanco, J. 2008. Modernidad conservadora y cultura política. La Acción Católica Argentina (1931-1941): Córdoba: Ferreyra Editor.

Bottinelli, L. et al 2001. «La JOC. El retorno de Cristo Obrero» en F. Mallimaci, R. Di Stefano, Roberto (comps.), Religión e imaginario social: Buenos Aires: Manantial.

Caggiano, A. 1951. Fundamentos doctrinales del Apostolado de los laicos. Lección dada en el Congreso Mundial del Apostolado de los laicos en Roma el 9 de octubre de 1951: Buenos Aires: Junta Central de ACA.

Caimari, L. 1995. Perón y la Iglesia Católica. Religión, Estado y sociedad en la Argentina (1943-1955): Buenos Aires: Ariel.

Ceamanos Llorens, R. 2002. «L'actualité de l'histoire (1951-1960). Historia del movimiento obrero, historia social». Hispania 210:299-329.

Cosse, I. 2006. Estigmas de nacimiento. Peronismo y orden familiar 1946-1955: Buenos Aires: FCE-Universidad de San Andrés.

Del Campo, H. 1983. Sindicalismo y peronismo. Los comienzos de un vínculo perdurable: Buenos Aires: Clacso.

Ganchegui, O., Derudi, N. 1953. Fundamentos de la JOC. Manual para dirigentes y asesores: Buenos Aires.

García Mourelle, L. 2001. «La Juventud Obrera Católica Femenina (JOCF) en Uruguay (1944-1960): su experiencia en el mundo del trabajo» en C. Touris (coord.), Actas de las Segundas Jornadas de Religión y Sociedad en la Argentina Contemporánea y países del Cono Sur (RELIGAR-SUR): Buenos Aires: editorial de la Facultad de Filosofía y Letras Universidad de Buenos Aires (CD-ROM).

Gené, M. 2005. Un mundo feliz. Imágenes de los trabajadores en el primer peronismo. 1946-1955: Buenos Aires: Fondo de Cultura Económica.

Karush, M. 2013. Cultura de clase. Radio y cine en la creación de una Argentina dividida (1920-1946). Buenos Aires: Ariel.

Rapalo, E. 2012. Patrones y obreros. La ofensiva de la clase propietaria, 19181930: Buenos Aires: Siglo XXI.

Vidal, G. 2012. «Asociacionismo Católico de Córdoba. Composición Social de las Comisiones Directivas del Círculo de Obreros de Córdoba, 1897- 1930» en G. Caretta, I. Zacca (comps.), Derroteros en la construcción de Religiosidades. Sujetos, instituciones y poder en Sudamérica, siglos XVII al XX: 197-218. Salta: ediciones del CEPIHA-UNSTA-CONICET. 